\title{
Prevalence of CYP2C19 681G >A and 636G >A Gene Polymorphisms in Javanese Farmers Exposed to Chlorpyrifos
}

\author{
Liem Jen Fuk, MD, PhD, ${ }^{1}$ Muchtaruddin Mansyur, MD, PhD, ${ }^{2}$ Safarina G. Malik, PhD, ${ }^{3}$ \\ Dwi A. Suryandari, PhD, ${ }^{4}$ Dewi S. Soemarko, MD, PhD, ${ }^{2}$ Imam Subekti, MD, PhD, ${ }^{5}$ \\ Franciscus D. Suyatna, MD, PhD, ${ }^{6}$ Aria Kekalih, MD, $\mathrm{PhD}^{2}$ and Bertha Pangaribuan, $\mathrm{PhD}^{7}$ \\ ${ }^{1}$ Department of Occupational Health and Safety, Faculty of Medicine and Health Science, Universitas Kristen Krida Wacana \\ ${ }^{2}$ Community Medicine Department, Faculty of Medicine Universitas Indonesia \\ ${ }^{3}$ Eijkman Institute for Molecular Biology, National Research and Innovation Agency \\ ${ }^{4}$ Department of Biology, Faculty of Medicine Universitas Indonesia \\ ${ }^{5}$ Department of Internal Medicine, Faculty of Medicine, Universitas Indonesia and Dr. Cipto Mangunkusumo General Hospital \\ ${ }^{6}$ Department of Pharmacology and Therapeutics, Faculty of Medicine Universitas Indonesia \\ ${ }^{7}$ Prodia Occupational Health Institute International
}

\begin{abstract}
Objective. The objective of our study was to determine the genotype frequencies of CYP2C19*2 and ${ }^{*} 3$ gene polymorphisms among Javanese farmers exposed to chlorpyrifos (CPF) in Central Java, Indonesia.

Methods. This cross-sectional study was conducted from July to October 2020 in Central Java, Indonesia, involving 151 vegetable farmers aged $18-65$ years who used CPF for at least one year. CYP2C19*2 and * 3 gene polymorphisms were analyzed using PCR-RFLP. Direct calculations were applied to calculate allele and genotype frequencies. The difference in genotype frequencies among the sex and cumulative exposure level (CEL) group was performed using the Chi-square test. In contrast, the proportion difference of allele frequencies was analyzed using Z-test.
\end{abstract}

Results. The frequency of CYP2C19 genotypes ${ }^{*} 1 /{ }^{*} 1,{ }^{*} 1 /{ }^{*} 3,{ }^{*} 1 /{ }^{*} 2$, and ${ }^{*} 2 /{ }^{*} 2$ were $64 \%, 7 \%, 23 \%$ and $6 \%$. We observed no significant difference in the genotype distribution according to sex group and CEL group.

Conclusion. In summary, the prevalence of toxicologically relevant CYP2C19 polymorphisms was determined in the Javanese agricultural population. The CYP2C19 genotype may be helpful as an essential biomarker of genetic susceptibility towards CPF exposure. Nevertheless, further studies to confirm the role of CYP2C19 in this context are still needed.

Key Words: CYP2C19, farmer, pesticide, susceptibility biomarker

\section{INTRODUCTION}

Indonesia is an agricultural country, and farmers generally use insecticides to control pests. The most widely used insecticide is chlorpyrifos $(\mathrm{CPF})$ and is most often used in vegetable farming and other crops like shallots, chilies, cocoa, soybeans, rice, and peanuts. ${ }^{1}$ Farmers' behavior in using insecticides is generally poor with higher concentrations and more frequent applications. Moreover, using multiple pesti-

Corresponding author: Liem Jen Fuk, MD, PhD Department of Occupational Health and Safety Faculty of Medicine and Health Science Universitas Kristen Krida Wacana Jalan Arjuna Utara No. 6, Kota Jakarta Barat, DKI Jakarta, Indonesia, 11510

Email: jenfuk.dr@gmail.com cides was a common practice. Still, proper personal protective equipment (PPE) use was rare otherwise. ${ }^{2}$ Farmer exposed to CPF may develop certain risks of health problems, including but not limited to neurological symptoms and hormonal alteration. $^{3,4}$ A recent report from a study on farmers in Central Java, Indonesia, revealed that $68.3 \%$ of participants 
had cholinesterase levels below the reference value indicating exposure to acetylcholinesterase inhibitor pesticides, and neuropathic symptoms were found in $59.2 \%$ of participants. ${ }^{5}$

Previous studies have elucidated the critical role of CYP450 (CYP) in the human bio metabolism of xenobiotic substances. Human CYP is known to have several essential effects regarding its role as a catalyst in phase 1 xenobiotic metabolism and clearance. ${ }^{6,7}$ However, it is not expressed at the same level for all individuals, thus impacting different individual responses to xenobiotics. Chlorpyrifos, an organophosphate $(\mathrm{OP})$ insecticide, is metabolically activated to its oxon form through bioactivation (desulfuration) reaction triggered by CYP2B6 and CYP3A4, and also can undergo a detoxification (dearylation) reaction, which is predominantly catalyzed by CYP2C19, resulting in inactive metabolites 3,5,6-Trichloro-2-pyridinol (TCPy). ${ }^{8,9}$ The balance between the activation and detoxification in $\mathrm{CPF}$ metabolism is affected by age, the co-existence of other xenobiotics, paraoxonase-1, CYP enzymes such as CYP2B6, and CYP2C19, then determine their toxic effects. ${ }^{10,11}$

Since the CYP2C19 gene is highly polymorphic and the * 2 and * 3 alleles are the most common variations in the CYP2C19 gene, such variations may alter the metabolic properties of the CYP2C19 enzyme (i.e., increased or reduced function) in the metabolism of many drugs and chemicals including CPF. ${ }^{10,12}$ Concerning the vital role of CYP2C19 in $\mathrm{CPF}$ metabolism, individuals with lower CYP2C19 expression due to the genetic variations may have a greater susceptibility to the effects of CPF exposure. ${ }^{13,14}$

Therefore, the objective of our study was to determine the genotype frequencies of $\mathrm{CYP} 2 \mathrm{C} 19 * 2$ and *3 gene polymorphisms among Javanese farmers exposed to CPF in Central Java, Indonesia. We hope our results will provide valuable and relevant information about the biomarker of susceptibility of CPF exposure and subsequently will be helpful in further exposure management, particularly in agricultural populations with extensive use of $\mathrm{CPF}$.

\section{MATERIALS AND METHODS}

All methods were performed following the relevant guidelines and regulations. The study protocol was approved by the Ethical Committee of the Faculty of Medicine Universitas Indonesia on March 23, 2020 (No. KET-339/ UN2.F1/ETIK/PPM.00.02/2020). Written informed consent was obtained from all study participants.

\section{Study population}

This cross-sectional study was held from July to October 2020. A consecutive sampling method was applied. We included 151 vegetable farmers from 2 villages, Pancot village, Tawangmangu District, and Adipuro village, Kaliangkrik District, known as the most prominent garlic and vegetable farming areas in Central Java, Indonesia, the study participants. The eligibility criteria were vegetable farmers who were actively using CPF for a minimum of 1 year before the study, aged between 18-65 years. They gave written consent to participate in the study. A small remuneration was given to the participants for their participation in this study.

\section{Characteristics of the study population and cumulative exposure level}

A structured interviewer-administered questionnaire was used to identify the individual and occupational characteristics of the study participants. We estimated the intensity level and cumulative exposure level (CEL) of CPF using a validated quantitative method in the Agricultural Health Study from Dosemeci. ${ }^{15}$ The intensity level was estimated as the function of activity related to the application (i.e., mixing, application method, repairing, washing, or both the equipment), use of PPE, gloves replacement, personal hygiene practices, and spill treatment when further combined with the lifetime years of pesticide use and the number of days spraying per year to estimate CEL. The participants were then classified as high and low exposure groups based on the median CEL value as described previously. ${ }^{2}$

\section{CYP2C19 Genotyping}

Genotyping assay was performed by Prodia Clinical Lab, Jakarta, Indonesia. Venous blood samples were collected from each participant using $3 \mathrm{~mL}$ EDTA anticoagulant tubes and then transported to the laboratory and stored at $-20^{\circ} \mathrm{C}$ before analysis. CYP2C19*2 (681G>A - rs4244285) and *3 (636G>A - rs4986893) were analyzed using Polymerase Chain Reaction-Restriction Fragment Length Polymorphism (PCR-RFLP) as described previously. ${ }^{16,17}$ During the RFLP phase, a specific restriction enzyme/ endonuclease was added to the DNA fragment and identified with electrophoresis gel. SmaI restriction enzyme was used in CYP2C19*2 analysis while primers forward 5'-CAGAGCTTGGCATATTGTATC-3' and 5'GTAAACACACAACTAGTCAATG - 3' as primers reverse were used in the PCR amplification process. In addition, BamHI restriction enzyme was used in CYP2C19*3 analysis, and the amplification process were done using primers forward 5'-AAATTGTTTCCAATCATTTAGCT-3' and reverse 5'-ACTTCAGGGCTTGGTCAATA-3'. The RFLP genotyping was visualized in Figure 1.

\section{Statistical Analysis}

The analysis was performed using SPSS 20 for Windows. The characteristics of the study population were described using mean (SD) or median (minimum-maximum). We directly calculated the allele and genotype frequencies. The CYP2C19 gene polymorphisms were classified as follows: ${ }^{*} 1 /{ }^{*} 1 ;{ }^{*} 1 /{ }^{*} 2 ;{ }^{*} 1 /{ }^{*} 3$; and ${ }^{*} 2 /{ }^{*} 2$. The difference in genotype frequencies among the sex and CEL group was performed using the Chi-square test, while the proportion difference of allele frequencies was analyzed using $Z$-test. All $p$ values were two-sided, with $\mathrm{p}<0.05$ was considered significant. 


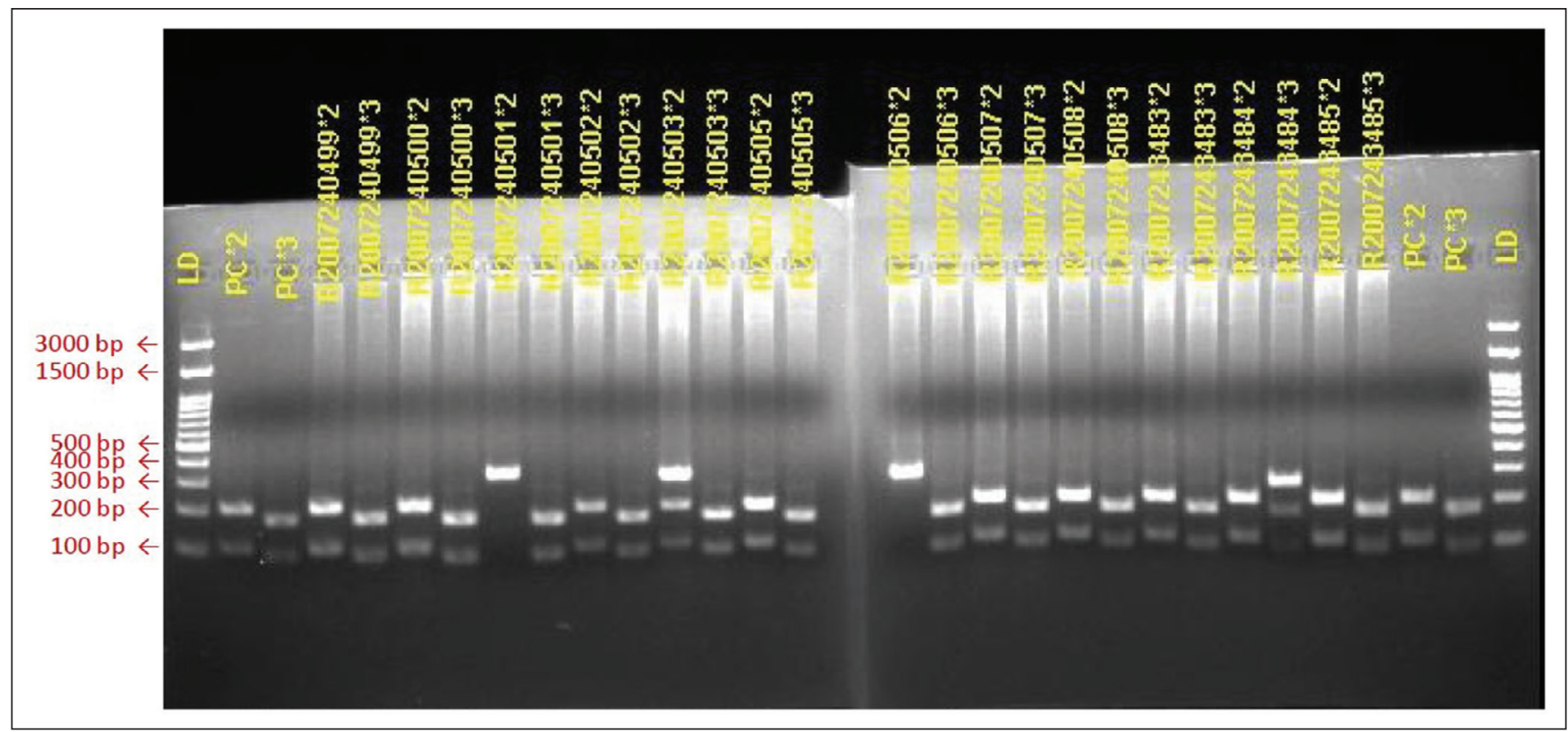

Figure 1. Visualization of CYP2C19 genotyping with PCR-RFLP.

\section{RESULTS}

Our study focused on determining the most common variant of the CYP2C19 allele associated with $\mathrm{CPF}$ exposure. We provide data regarding the distribution of the most common and clinically significant allelic and genotypic frequency of CYP2C19*2 (681G>A) and *3 (636G >A) in Javanese agricultural populations.

The mean age of our study population was 50 (SD 9.4) years and the median of lifetime years of pesticide use was 25 (1-45) years. Among them, 91\% were male, and 47\% were classified as a high CEL group. The observed frequency of the CYP2C19 genotype was in Hardy-Weinberg equilibrium. The frequency of CYP2C19 genotypes * $1 / * 1$, ${ }^{*} 1 /{ }^{*} 3,{ }^{*} 1 /{ }^{*} 2$, and ${ }^{*} 2 /{ }^{*} 2$ were $64 \%, 7 \%, 23 \%$ and $6 \%$, respectively as shown in Table 1.

The *2/*3 haplotypes were not found in our population. We observed no significant difference in the genotype distribution according to sex group (Table 2) and CEL group (Table 3), indicating that the members of both groups shared a similar genetic susceptibility to $\mathrm{CPF}$ exposure.

As shown in Table 4, our findings indicated that reduced function alleles were present in $21 \%$ of our study population. The CYP2C19*2 minor allele frequency (MAF) was $17.5 \%$, while MAF for *3 allele was $3.6 \%$.

\section{DISCUSSION}

The distribution of CYP2C19 gene polymorphisms has been previously studied in various populations. The frequency of the wildtype CYP2C19 allele in the Asian population is $60.5 \%$. The most common allele was ${ }^{*} 2$ with
Table 1. Distribution of CYPC19 genotype in study population

\begin{tabular}{ccc} 
Genotype & Frequency $(\mathbf{n}=\mathbf{1 5 1})$ & Expected Phenotype \\
\hline AA $\left({ }^{*} 2 /{ }^{*} 2\right)$ & $9(6,0)$ & Poor Metabolizer (PM) \\
GA $\left({ }^{*} 1{ }^{*} 2\right)$ & $35(23,2)$ & Intermediate Metabolizer (IM) \\
GA $\left({ }^{*} 1{ }^{*} 3\right)$ & $11(7,3)$ & Intermediate Metabolizer (IM) \\
GG $\left({ }^{*} 1 * 1\right)$ & $96(63,6)$ & Extensive Metabolizer (EM) \\
\hline
\end{tabular}

Table 2. Distribution of CYPC19 genotype according to the sex group

\begin{tabular}{lccc}
\multirow{2}{*}{ Genotype } & \multicolumn{2}{c}{ Sex group } & \multirow{2}{*}{ ps $^{\text {cs }}$} \\
\cline { 2 - 3 } & Female $(\mathbf{n}=14)$ & Male $(\mathbf{n}=137)$ & 0.559 \\
AA $\left({ }^{*} 2 /{ }^{*} 2\right)$ & $0(0)$ & $9(6,6)$ & \\
GA $\left({ }^{*} 1{ }^{*} 2\right)$ & $5(35,7)$ & $30(21,9)$ & \\
GA $\left({ }^{*} 1 /{ }^{*} 3\right)$ & $1(7,1)$ & $10(7,3)$ & \\
GG $\left({ }^{*} 1 * 1\right)$ & $8(57,1)$ & $99(64,2)$ & \\
\hline
\end{tabular}

${ }^{\#} n$ (\% within sex group)

cs - Chi-square for testing of male and female group

Table 3. Distribution of CYPC19 genotype according to CEL

\begin{tabular}{lccc}
\multirow{2}{*}{ Genotype } & \multicolumn{2}{c}{ Cumulative exposure level } & \multirow{2}{*}{ p $^{\text {cs }}$} \\
\cline { 2 - 3 } & High $(\mathbf{n}=71)$ & Low $(\mathbf{n}=80)$ & 0.580 \\
$\mathrm{AA}\left({ }^{*} 2 /{ }^{*} 2\right)$ & $3(4,2)$ & $6(7,5)$ & \\
$\mathrm{GA}\left({ }^{*} 1{ }^{*} 2\right)$ & $14(19,7)$ & $21(26,2)$ & \\
$\mathrm{GA}\left({ }^{*} 1 /{ }^{*} 3\right)$ & $6(8,5)$ & $5(6,2)$ & \\
$\mathrm{GG}\left({ }^{*} 1^{*} 1\right)$ & $48(67,6)$ & $48(60,0)$ & \\
\hline
\end{tabular}

\# $n$ (\% within CEL group)

cs - Chi-square for testing of high and low CEL group 
Table 4. The minor allele frequency of CYP2C19*2 and * 3 gene polymorphisms and the genotype frequencies of CYP2C19*2 and $* 3$ in different population

\begin{tabular}{|c|c|c|c|c|c|c|c|}
\hline \multirow{2}{*}{ Population } & \multirow{2}{*}{ Sample size } & \multicolumn{2}{|c|}{ MAF CYP2C19 (\%) } & \multicolumn{4}{|c|}{ Genotype CYP2C19 (\%) } \\
\hline & & $681 \mathrm{G}>\mathrm{A}$ & $636 \mathrm{G}>\mathrm{A}$ & ${ }^{*} 1 /{ }^{* 1}$ & ${ }^{*} 1 /{ }^{*} 2$ & ${ }^{*} 1 /{ }^{*} 3$ & ${ }^{*} 2 /{ }^{*} 2$ \\
\hline Present study & 151 & 17.5 & 3.6 & 63.6 & 23.2 & 7.3 & 6.0 \\
\hline Egyptian $^{18}$ & 120 & $3.8^{\#}$ & $0.0^{\#}$ & $93.3^{\#}$ & $5.8^{\#}$ & $0.0^{*}$ & $0.8^{\#}$ \\
\hline Han Chinese ${ }^{19}$ & 100 & 25.5 & 2.0 & $42.0^{\#}$ & $41.0^{\#}$ & $3.0^{\#}$ & 3.0 \\
\hline Thai $^{20}$ & 1205 & $25.6^{\#}$ & 2.5 & $48.2^{\#}$ & $37.9^{\#}$ & $3.5^{\#}$ & 5.3 \\
\hline Kinh Vietnamese ${ }^{21}$ & 100 & 20.5 & 2.5 & 58.0 & 32.0 & 4.0 & 3.0 \\
\hline
\end{tabular}

\# $p<0.05$ by Z-test indicates a significant difference of MAF or genotype frequencies compared to the present study

an allele frequency of more than $70 \%$, followed by ${ }^{*} 17$, and *3. ${ }^{14}$ The minor allele frequency (MAF) of CYP2C19*2 and $* 3$ in our study was similar to that of the Han Chinese and Kinh Vietnamese population, but particularly lower *2 MAF than Thai. CYP2C19*3 is considered an Asian mutation, so, understandably, no *3 allele was found among the Egyptians. ${ }^{22}$ Our findings indicate that the prevalence of poor metabolizers in this study was significantly higher than that of Egyptians and higher than those of HanChinese, Thai, and Kihn-Vietnamese Kinh, although not significantly different.

Individual responses to xenobiotics may be influenced by genetic polymorphisms in genes encoding enzymes that play a role in phase 1 and phase 2 metabolism, particularly enzymes catalysing the oxidation and conjugation reactions. This condition explained the activity of the bioactivation of xenobiotics to form products that are more reactive than the parent compound but can also promote the detoxification process and facilitate the subsequent excretion process. ${ }^{12}$ Four phenotypes have been identified for CYP2C19 according to their enzyme activity, i.e., extensive metabolizer (EM), intermediate metabolizer (IM), poor metabolizer (PM), and ultra-rapid metabolizer (UM). ${ }^{12,23}$

The CYP2C19*2 and *3 gene polymorphisms were present in 1 out of 3 among our study population. We found that $30 \%$ of the studied population could be categorized as intermediate metabolizers since their genotype contained one reduced function allele $\left({ }^{*} 1 /{ }^{*} 2\right.$ or $\left.{ }^{*} 1 /{ }^{*} 3\right)$. In contrast, the other $6 \%$ with two reduced function alleles $\left({ }^{*} 2 /{ }^{*} 2\right)$ can be classified as poor metabolizers. Since the CYP2C19 has a significant role in the detoxification process of $\mathrm{CPF}$ to form the inactive metabolite TCPy, individuals with genetic variations of $\mathrm{CYP} 2 \mathrm{C} 19 * 2$ and $* 3$ was thought to have lower enzymatic activity resulting in decreased $\mathrm{CPF}$ detoxification capacity. ${ }^{10,12} \mathrm{CYP} 2 \mathrm{C} 19^{*} 2$ is the result of a $\mathrm{G}>\mathrm{A}$ transition at position 681 in exon 5 which causes a splicing defect in pre-RNA that affects the proline amino acid at position 227. In contrast, CYP2C19*3 is a $\mathrm{G}>\mathrm{A}$ transition at position 636 in exon 4 , a vital point mutation due to replacing the tryptophan codon TGG with TGA. Both variants produce premature stop codons and, of course, non-functional proteins. ${ }^{23}$
With a better understanding of the CPF metabolic pathways, the human population's significant risks resulting from CPF exposure can be estimated. The metabolism of $\mathrm{CPF}$, mainly the detoxification process, is quite complex, with many enzymes involved. Thus, with CYP2C19 as the main enzymes involved in this process, the CYP3A4 and $1 \mathrm{~A} 2$ also play a role in the CPF detoxification reactions. ${ }^{10,24}$ Individuals with low levels of CYP2C19 can be expected to produce fewer dearylation products. Therefore, intermediate or poor metabolizer individuals with lower CYP2C19 expression may be more susceptible to the effects of $\mathrm{CPF}$ exposure, ${ }^{13}$ as the $\mathrm{CPF}$ parent compound is more readily available for bioactivation.

Our study has limitations as we did not examine other CYP isoforms that are important in CPF detoxification, i.e., CYP3A4 and CYP1A2, as potential genetic risk factors, so it is not clear how these CYP variants will interact with each other.

\section{CONCLUSION}

In summary, our results provide a basic profile, the prevalence of toxicologically relevant CYP2C19 polymorphisms in the Javanese agricultural population. These results provide information on most polymorphisms in genes encoding essential enzymes involved in CPF metabolism that may lead to the health impacts of occupational exposure to CPF among farmers' populations. Because the prevalence of CYP2C19*2 and *3 was considered high in this farming population, a periodic medical examination needs to be implemented to maintain farmers' health and early detection of the potential health problems. The CYP2C19 genotype may be helpful as an essential biomarker of genetic susceptibility towards CPF exposure. Nevertheless, further studies to confirm the role of CYP2C19 in this context are still needed.

\section{Statement of Authorship}

All authors participated in the data collection and analysis and approved the final version submitted. 


\section{Author Disclosure}

All authors declared no conflicts of interests.

\section{Funding Source}

The authors received financial support from Prodia Group. The funders had no role in the study's design, in the collection, analysis, and interpretation of data, or in the writing of the manuscript and the decision to publish.

\section{REFERENCES}

1. Casida JE, Bryant RJ. The ABCs of Pesticide Toxicology: Amounts, Biology, and Chemistry. Toxicol Res (Camb). 2017;6:755-63.

2. Liem JF, Mansyur M, Soemarko DS, Kekalih A, Subekti I, Suyatna FD, et al. Cumulative Exposure Characteristics of Vegetable Farmers Exposed to Chlorpyrifos in Central Java - Indonesia; A Cross-sectional Study. BMC Public Health. 2021;21:1066.

3. Khan K, Ismail AA, Abdel Rasoul G, Bonner MR, Lasarev MR, Hendy O, et al. Longitudinal Assessment of Chlorpyrifos Exposure and Self-reported Neurological Symptoms in Adolescent Pesticide Applicators. BMJ Open. 2014;4:e004177.

4. Ventura C, Nieto MR, Bourguignon N, Lux-Lantos V, Rodriguez H, Cao G, et al. Pesticide Chlorpyrifos Acts as an Endocrine Disruptor in Adult Rats Causing Changes in Mammary Gland and Hormonal Balance. J Steroid Biochem Mol Biol. 2016;156:1-9.

5. Setyopranoto I, Argo IW, Ramadhani AF, Dwianingsih EK, Tama WN, Gofir A, et al. The Association between Pesticide Exposure and Neurological Signs and Symptoms in Farmers in Magelang District, Central Java, Indonesia. Open Access Macedonian Journal of Medical Sciences. 2020;8:538-43.

6. Teodoro M, Briguglio G, Fenga C, Costa C. Genetic Polymorphisms as Determinants of Pesticide Toxicity: Recent Advances. Toxicol Rep. 2019;6:564-70.

7. Nelson DR, Nebert DW. Cytochrome P450 (CYP) gene superfamily. eLS2018. p. 1-19.

8. Croom EL, Wallace AD, Hodgson E. Human Variation in CYPspecific Chlorpyrifos Metabolism. Toxicology. 2010;276:184-91.

9. Rendic SP, Guengerich FP. Human Family 1-4 cytochrome P450 Enzymes Involved in the Metabolic Activation of Xenobiotic and Physiological Chemicals: an Update. Arch Toxicol. 2021;95:395-472.

10. Crane AL, Klein K, Zanger UM, Olson JR. Effect of CYP2B6*6 and CYP2C19*2 Genotype on Chlorpyrifos Metabolism. Toxicology. 2012;293:115-22.

11. Liem JF. Biomonitoring Pajanan Pestisida Organofosfat pada Pekerja Pertanian. J Kdokt Meditek. 2021;27:88-94.

12. Johansson I, Ingelman-Sundberg M. Genetic Polymorphism and Toxicology-with Emphasis on Cytochrome P450. Toxicol Sci. 2011;120:1-13.
13. Foxenberg RJ, Ellison CA, Knaak JB, Ma C, Olson JR. Cytochrome P450-specific Human PBPK/PD Models for the Organophosphorus Pesticides: Chlorpyrifos and Parathion. Toxicology. 2011;285:57-66.

14. Zhou Y, Ingelman-Sundberg M, Lauschke VM. Worldwide Distribution of Cytochrome P450 Alleles: A Meta-analysis of Population-scale Sequencing Projects. Clin Pharmacol Ther. 2017;102:688-700.

15. Dosemeci M, Alavanja MC, Rowland AS, Mage D, Zahm SH, Rothman N, et al. A Quantitative Approach for Estimating Exposure to Pesticides in the Agricultural Health Study. Ann Occup Hyg. 2002;46:245-60.

16. Goldstein J, Ishizaki T, Chiba K, de Morais S, Bell D, Krahn P, et al. Frequencies of the Defective CYP2C19 Alleles Responsible for the Mephenytoin Poor Metabolizer Phenotype in Various Oriental, Caucasian, Saudi Arabian and American Black Populations. Pharmacogenetics. 1997;7:59-64.

17. de Morais SM, Wilkinson GR, Blaisdell J, Nakamura K, Meyer UA, Goldstein JA. The major genetic defect responsible for the polymorphism of S-mephenytoin metabolism in humans. Journal of Biological Chemistry. 1994;269:15419-22.

18. Ellison CA, Abou El-Ella SS, Tawfik M, Lein PJ, Olson JR. Allele and genotype Frequencies of CYP2B6 and CYP2C19 Polymorphisms in Egyptian Agricultural Workers. J Toxicol Environ Health A. 2012;75:232-41.

19. Zhou Q, Yu XM, Lin HB, Wang L, Yun QZ, Hu SN, et al. Genetic Polymorphism, Linkage Disequilibrium, Haplotype Structure and Novel Allele Analysis of CYP2C19 and CYP2D6 in Han Chinese. Pharmacogenomics J. 2009;9:380-94.

20. Sukprasong R, Chuwongwattana S, Koomdee N, Jantararoungtong T, Prommas S, Jinda P, et al. Allele Frequencies of Single Nucleotide Polymorphisms of Clinically Important Drug-metabolizing Enzymes CYP2C9, CYP2C19, and CYP3A4 in a Thai Population. Sci Rep. 2021;11:12343.

21. Vu NP, Nguyen HTT, Tran NTB, Nguyen TD, Huynh HTT, Nguyen XT, et al. CYP2C19 Genetic Polymorphism in the Vietnamese Population. Ann Hum Biol. 2019;46:491-7.

22. Hamdy SI, Hiratsuka M, Narahara K, El-Enany M, Moursi $\mathrm{N}$, Ahmed MS-E, et al. Allele and Genotype Frequencies of Polymorphic Cytochromes P450 (CYP2C9, CYP2C19, CYP2E1) and Dihydropyrimidine Dehydrogenase (DPYD) in the Egyptian Population. Br J Clin Pharmacol. 2002;53:596-603.

23. Brown SA, Pereira N. Pharmacogenomic Impact of CYP2C19 Variation on Clopidogrel Therapy in Precision Cardiovascular Medicine. J Pers Med. 2018;8.

24. Kaur G, Jain AK, Singh S. CYP/PON Genetic Variations as Determinant of Organophosphate Pesticides Toxicity. J Genet. 2017;96:187-201. 